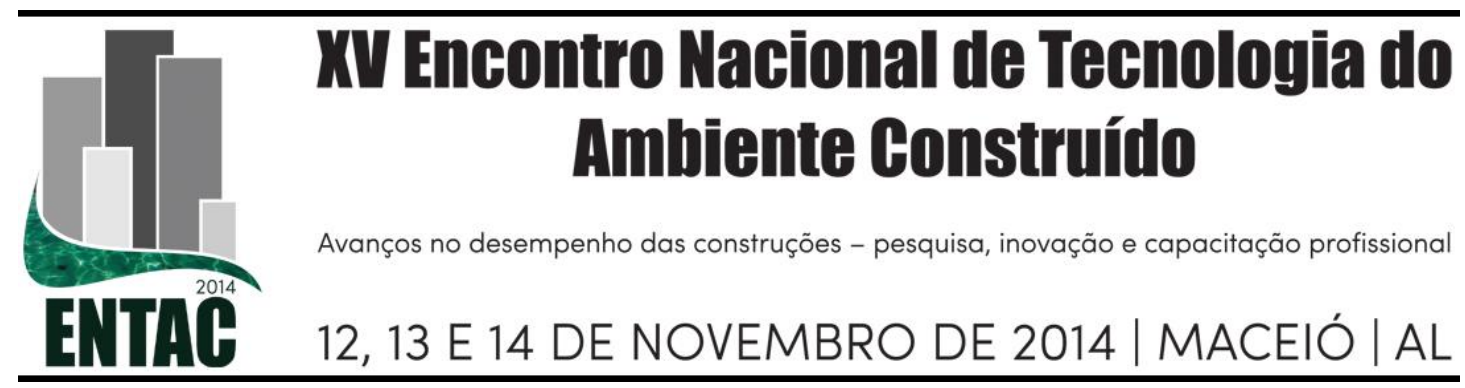

\title{
AUTOMAÇÃO RESIDENCIAL: DIRETRIZES PARA MANUAL PÓS-INSTALAÇÃO.
}

\author{
VALQUES, Igor José Botelho (1); BARBOSA, Ariela (2); VALQUES, Paula Grace \\ Correia (3); SOARES, Paulo Fernando (4); CARAM, Rosana Maria (5) \\ (1) UEM, (44)3011-4429, ijbvalques@uem.br (2) UNIPAR, ariela@unipar.br (3) FEITEP, \\ paula_grace@msn.com (4)UEM, pfsoares@uem.br (5)USP,rmcaram@usp-sc.br
}

\begin{abstract}
RESUMO
A automação é uma inovação? Segundo o Manual de Oslo ela pode ser designada como inovação tecnológica de produto, mais especificamente a de um produto tecnologicamente aprimorado. Pois, ao se utilizar de módulos de comando que ordenam e gerenciam as ações necessárias à automatização de elementos e equipamentos, tem-se um produto tecnologicamente aprimorado, evoluído da automação industrial, e uma inovação incremental na área da construção civil. Entretanto, pode-se afirmar que esta gera também uma inovação de processo, pois, forçosamente implicará em inovações no campo de marketing, vendas e suporte ao cliente. Este trabalho teve como objetivo estabelecer diretrizes para um manual do cliente pós-instalação à Automação Residencial. Como método optou-se pela entrevista, que foi feita a quatro clientes e seus familiares, de uma empresa especializada em automação residencial, frente ao produto instalado em uma abordagem indutiva. Analisadas as respostas avaliou-se o entendimento sobre a integração dos sistemas instalados, o desempenho de sistemas, as interfaces possíveis e o conhecimento sobre os equipamentos instalados, tendo como contexto o dia-a-dia da utilização do sistema de automação pelo cliente final. Verificou-se que o resultado veio ao encontro da percepção intuitiva dos pesquisadores. Aferiu-se que no momento da pós-instalação e na utilização continua dos equipamentos, surgem dúvidas que podem, por fim, gerar manuseio errôneo que levam a alterações indesejadas no sistema. Este trabalho possibilitou conhecer o número de informações necessárias que expressam a apreensão do sistema de automação, sua percepção e memorização nas obras escolhidas. Justificativa suficiente para a elaboração de um manual pós-instalação exclusivo para cada usuário. Sendo que inexiste um Manual Pós-Instalação nesta área, e que este auxiliará a consolidação deste processo inovador, espera-se que este artigo seja uma contribuição para o integrador, planejador ou gestor de projetos e, por fim, para o usuário, no que tange o entendimento perceptivo desta inovação tecnológica.
\end{abstract}

Palavras-chave: Automação predial, Inovação tecnológica, Manual pós-instalação.

\begin{abstract}
Automation is an innovation? According to the Oslo Manual it can be designated as a technological product, specifically a technologically improved product. Well, when using command modules that order and manage the necessary elements of the automation equipment and actions, has become a product evolved from industrial automation, and an incremental innovation in construction. However, it can be stated that this also generates an innovation process therefore necessarily imply innovations in the field of marketing, sales and customer support. This study aimed to establish regulations for the post-installation customer to Home Automation manual. As a method was chosen for the interview, which was taken to four clients and their families, a company specializing in home automation, opposite the product installed in an inductive approach. Analyzed the responses evaluated the understanding of the integration of the installed systems, performance systems, the possible interfaces and knowledge regarding the equipment installed, with the context the day-to-day use of the automation system by the end customer. It was found that the results coincided with the intuitive perception of the researchers. It measured is that at the time of the postinstallation and continued use of the equipment, there is concern that can ultimately generate erroneous handling leading to unwanted changes in the system. This study has helped understand the number of
\end{abstract}


necessary information expressing the apprehension of the automation system, their perception and memorizing the chosen work. Sufficient for the development of a unique post-installation manual for each user justification. Since no overall Post-Installation Manual in this area, and this will help the consolidation of this innovative process, it is hoped that this article is a contribution to the integrator, planner or project manager and, finally, to the user, as regarding the perceptual understanding of this technological innovation

Keywords: Building automation, technological innovation, Manual post-installation.

\section{INTRODUÇÃO}

Em um projeto de automação residencial, existem vários fatores a serem levados em consideração como infraestrutura necessária, definição dos serviços e componentes, procedimentos de instalação, normas técnicas e outras recomendações que irão assegurar a longevidade do sistema instalado, seu desempenho e segurança para que este suporte uma grande variedade de aplicações do sistema automação visando a qualidade e eficiência das ambiências propiciadas (SENA, 2005; DA SILVA, 2009).

Nesse sentido, as ambiências criadas ou possibilitadas pela automação residencial além de condicionarem comportamentos pessoais (sensor de movimento $\mathrm{x}$ iluminação do ambiente) motivam e emocionam conforme seu caráter (iluminação cênica $\mathrm{x}$ detectores de impulsos sonoros). Afinal, segundo Schmid (2005) o proprietário de uma casa quer, em primeira linha, o conforto dos ambientes. No entanto, no dia a dia do uso do sistema de automação decisões e acionamentos, inerentes ao usuário, podem acarretar vários percalços na relação empresa/cliente dependendo do grau de apreensão desta nova tecnologia.

Segundo o Manual de Oslo (2005), recai sobre a automação a alcunha de inovação tecnológica de produto, mais especificamente a de um produto tecnologicamente aprimorado. Pois, ao se utilizar de módulos de comando que ordenam e gerenciam as ações necessárias à automatização de elementos e equipamentos, tem-se um produto tecnologicamente aprimorado da automação industrial, e uma inovação incremental na área da construção civil. Entretanto, pode-se afirmar que gera também uma inovação de processo, pois, forçosamente implicará em inovações no campo de marketing, vendas e suporte ao cliente.

Tendo em vista o suporte ao cliente, objetivou-se, com esta pesquisa, definir diretrizes para nortear a elaboração de um manual pós-instalação para usuários de casas automatizadas. Especificamente conhecer as características desta inovação incremental e interpretar os indicadores situacionais que balizam o entendimento da automação pelo usuário. Este trabalho justificou-se, pois, busca maximizar a qualidade avaliativa dos espaços edificados, para auxiliar a mitigar ou até minimizar os efeitos da fobia tecnológica na vida dos usuários/proprietários. Como método de pesquisa, levantaram-se as dúvidas pontuais, mas frequentes, de quatro clientes e seus familiares de uma empresa especializada em automação residencial, frente ao produto instalado. Por fim, estabeleceram-se itens fundamentais que devem constar de um recomendável manual pós-instalação que veem ao encontro deste processo inovador: a automação predial.

\section{AUTOMAÇÃO INSTALADA}

Entende-se por automação um conjunto de técnicas que podem ser aplicadas sobre um processo objetivando torná-lo mais integrado e eficiente, ou seja, maximizando o trabalho com menor consumo de energia, menor emissão de resíduos e, melhores condições de segurança, tanto humana e material quanto das informações inerentes ao processo (FERRARI et al. 2009). 
A automação integra ações, equipamentos, enfim integra ambientes no cerne da sua gênese residencial. Habitar em ambientes inteligentes é vivenciar perante a diversidade de "[...] sensores, atuadores e dispositivos que, quando conectados de forma pertinente, possibilitam o desenvolvimento de inúmeros serviços, sistemas e métodos de gestão da residência" (BOLZANI, 2004, p.23). Ainda nesse ideário, a automação residencial é, conforme Sena (2005, p.13), a união "[...] de novas tecnologias que integradas, procuram oferecer conforto, praticidade, produtividade, economia, eficiência e rentabilidade, com valorização da imagem do empreendimento e de seus usuários".

As cenas criadas na casa inteligente podem, quando em total harmonia com o usuário, serem para divertir, informar, revelar, intimidar, ovacionar, apaixonar ou simplesmente contemplar. De acordo com Tuan (1980, p.82), o ser humano, “[...] constrói um ambiente artificial resultado de processos mentais (mitos, fábulas, ciência) para se sentir confortável na natureza". Possibilidades que tornam as ambiências propiciadas pela automação um fator subjetivo, mas com grande força decisória e avaliativa. Afinal, o usuário de uma casa automatizada quer, em primeira linha, o conforto que a casa inteligente pode propiciar é o atual auge de interação homem/ambiente construído que responde pela conectividade total almejada.

Segundo Bolzani (2004) e Sena (2005) algumas das características fundamentais que se deve encontrar num sistema inteligente são: a capacidade para integrar todos os sistemas; possuir memória funcional; ter fácil relação com o usuário e facilidade de reprogramação. Entende-se que essas características podem ser avaliadas e, por conseguinte balizar o objetivo deste trabalho que é estabelecer diretrizes para a elaboração de um manual pósinstalação. Nesse sentido, discorre-se sobre as características que serão utilizadas como "macros indicadores" das entrevistas para avaliar o sistema de automação instalada em residências, objeto desta pesquisa.

\subsection{Integração de sistemas}

A automação residencial possibilita a integração dos sistemas envolvidos (segurança, iluminação, conforto ambiental, entretenimento, etc.). Assim, os projetos destinados a este fim tiram partido dessa contingencia para propiciar diferentes combinações que facilitem e auxiliem o dia-a-dia do usuário em suas tarefas, no lazer ou simplesmente na vivência nos ambientes construídos.

[...] Numa rede de comunicações de dados (...), os mesmos sensores que detectam movimento, fogo, ou líquidos podem ativar um número variado de ações. Caso haja a necessidade, o sistema de segurança pode controlar o ar-condicionado e a ventilação (desligando-os em caso de incêndio), destrancando as portas e janelas. (BOLZANI, 2004, p.72).

Deste modo deverá haver concordância entre os sistemas integrados pela automação a fim de que os softwares envolvidos tenham compatibilidade entre si na rede residencial instalada. "Assim, é normal que o usuário final anseie (...) comandar individualmente cada um dos subsistemas, mas também executar comandos mais complexos envolvendo todas as possibilidades" (MURATORI, 2012, p.01). Esta imposição é a necessidade básica para ter-se uma integração de sistemas condizente com os anseios do usuário e cliente, em função das possibilidades que a automação pode oferecer.

\subsection{Desempenho do sistema}

A avaliação de um sistema automatizado pelo usuário pode ser obtida pela funcionalidade do mesmo. Também pela robustez frente às várias adversidades situacionais relacionadas ao uso e a instalação. Ainda a fatores externos, tais como: interrupção abrupta de energia, 
tempestades ou manuseio do quadro de automação por leigos. Como também pela eficácia no gerenciamento de vários sistemas. Este fato gera economia de energia e aperfeiçoa a qualidade dos espaços que foram automatizados. Pois, acrescenta Bolzani (2004):

[...] consegue-se alterar os horários de funcionamento dos equipamentos automaticamente, em função dos resultados de conforto obtidos e das condições meteorológicas externas, de forma que os grandes consumidores de eletricidade, tais como aquecedores e climatizadores modifiquem suas curvas de produção obtendo-se resultados mais eficientes (BOLZANI, 2004, p.109).

Entretanto, ainda consoante a Bolzani (2004, p.27), “[...] não interessa quão sofisticado seja o programa para atender todas as necessidades, ele de alguma forma, em alguma ocasião, vai agir de forma inesperada e indesejada, frustrando os ocupantes". Atualmente, conforme explana Bolzani (2004, p.109), "[...] é possível ter acesso a toda a informação de gestão de uma casa de forma eficaz com programas totalmente interativos, o que possibilita fazer modificações com grande facilidade". (BOLZANI, 2004, p.27).

\subsection{Interfaces casa/usuário}

A maioria dos sistemas de automação, conforme Sena (2005), possibilitam serem remotamente controlados através de conexão via internet. Para tanto, a interação usuário/automação deve ser de fácil entendimento e compatível com a toda gama de tarefas que são ofertadas pelo sistema. Conforme Muratori e Dal Bó (2011) a interface que mais seja associada à automação residencial seja o controle remoto universal. Segundo Vargas (2004, apud OSÓRIO et al, 2005, p.09):

[...] no ambiente doméstico são necessárias interfaces e sistemas muito amigáveis, simples de manusear e flexíveis para se ajustarem às necessidades dos usuários. Isso aumenta o grau de dificuldade da implementação de sistemas residenciais, uma vez que sua concepção traz essa variável subjetiva adicional, evidenciada na relação do usuário com a tecnologia.

Nesse prisma de ideias, Leitte et al $(2012$, p.06) afirma que: “[...] pode-se concluir que a automação residencial se configura num desafio do presente, devendo prover ao usuário interfaces amigáveis e descomplicadas [...]", como também continua o autor "[...] disponibilizar a informação e possibilidade de controle da residência a partir de qualquer lugar, [...] para colocar em primeiro plano a sociabilidade e bem-estar do usuário". Assim, nasce o ideário para o Manual Pós-Instalação para residências inteligentes via automação.

\subsection{Manual pós-instalação}

Como explanado a casa automatizada ou inteligente demanda uma interface com o usuário, cujo manuseio deve ser apreendido durante a instalação e no momento de entrega do sistema de automação pela empresa contratada. Nesse ideário, o comprador do sistema e futuro usuário deverá memorizar inúmeros comandos que se relacionam entre si, propiciando inúmeras cenas ou situações pré-determinadas.

Lembra-se que a NBR 14037, que trata das "Diretrizes para elaboração de manuais de uso, operação e manutenção das edificações", a elaboração do manual deve ser de responsabilidade do construtor. O item 7.3 explicita em subitem que o manual deve ser entregue "[...] um exemplar do manual com informações julgadas necessárias sobre sistemas, elementos e componentes, instalações e equipamentos de áreas comuns de cada unidade autônoma aos seus proprietários", incluindo o conjunto completo de projetos atualizados (ABNT, 1998, p.05). 
Nas palavras de Paula Filho (2000) apresentação ou recuperação de informações pode ser de maneira multissensorial (através dos sentidos da audição e da visão), integrada (por texto, som e imagem relacionados), intuitiva (por uso de ícones) e a interativa (através de várias possibilidades de navegação para o usuário). Nessa linha, De Araújo (2001) afirma que a ISO-9001 (2000) "que trata de Sistema de Gestão da Qualidade (SGQ), apresenta no item 7.2.4 que trata da comunicação com o cliente o seguinte texto":

[...] verifica-se que atender às necessidades dos clientes é uma obrigação da empresa, principalmente se esta estiver desenvolvendo esforços para obtenção de um grau de certificação internacional. E ainda, superar as expectativas de seus clientes pode ser o melhor marketing [...] (ISSO-9001 apud DE ARAÚJO, 2001, p.02-03).

Elucida-se que, possivelmente, mesmo após toda a demonstração e explicação dada pela empresa instaladora do sistema de automação, o comprador sentir-se-á inserido num mundo desconhecido. A falta de memória ou o desconhecimento de situações novas podem acarretar ansiedade e aborrecimentos (TOFLEER, 1973). A necessidade de um auxílio na memorização, das opções do sistema de automação instalado parece ser claro e premente para o bom relacionamento comprador/empresa como também para a continuidade de venda. Nesse sentido, discorre-se a seguir sobre o estudo de caso que embasou as diretrizes para o Manual Pós-instalação proposto.

\section{CASE: QUATRO RESIDÊNCIAS AUTOMATIZADAS}

A empresa que foi utilizada nesta pesquisa nasceu em 2010 com a finalidade de comercializar produtos para "automação de residências". Derivada de uma empresa de vendas de aparelhos para home-theater, houve aprimoramento por parte dos sócios que se capacitaram na nova tecnologia, além da implantação de um showroom especializado na demonstração da inovação incremental aos espaços que seria comercializada a automação residencial. A empresa pesquisada tem obras em andamento, obras prontas e projetos sendo feitos. Preferiu-se a pesquisas aos usuários de obras já entregues, pois, vão ao encontro do objetivo deste artigo que é estabelecer as diretrizes de um Manual pósinstalação no que tange sua necessidade como meio de contato, informação e manutenção do sistema de automação instalado.

As obras visitadas, quatro no total, são residências construídas em condomínios fechados na cidade de Maringá, Paraná, onde a empresa pesquisada instalou sistemas diferenciados de automatização. A empresa responsável pela implantação do sistema, além de dar suporte ao cliente, também realizou um trabalho junto aos projetistas responsáveis para esclarecimentos sobre a diferença entre projetos com e sem automação residencial, suas funções e modificações ainda na planta arquitetônica executiva.

Todas as residências escolhidas já tinham tido um uso do sistema de automação superior a seis meses. Respeitando-se a não exposição da identidade dos proprietários, nominarse-ão simplesmente siglas para Residência Automatizada (RA) acrescida de índice específico.

Na residência RA1, têm-se quatro usuários que utilizarão o sistema de automação: o casal proprietário e os filhos já adultos. Na residência RA2, têm-se, no entanto, três usuários: o casal proprietário e a filha de quatorze anos. Na residência RA3, têm-se quatro usuários: o casal proprietário e os filhos adolescentes. Na residência RA4, têm-se também quatro usuários: o casal proprietário, o filho adolescente e o pai do proprietário. 


\subsection{As entrevistas com usuários}

A pesquisa de campo (verificação, levantamento, monitoramento in loco), indica Marconi \& Lacatos (2006, p.84) "[...] é aquela utilizada com o objetivo de conseguir informações e/ou conhecimentos acerca de um problema para o qual se procura uma resposta". Ou, continuam as autoras, "[...] de uma hipótese que se queira comprovar, ou, ainda descobrir novos fenômenos ou as relações entre eles".

A pesquisa deste trabalho aconteceu em quatro dias diferentes e foi baseada em uma pesquisa anterior, com o mesmo objetivo, feita em junho de 2012. Reproduziu-se a entrevistas com os clientes alterando a forma de análise e os eixos temáticos abordados. Gentilmente todos aceitaram responder, novamente, uma gama de perguntas.

As entrevistas foram agendadas previamente e ocorreram durante o mês de dezembro de 2013, basicamente em finais de semana. Com isso obteve-se, como universo de pesquisa, 15 pessoas entrevistadas. As entrevistas foram feitas partir de um questionário previamente elaborado com perguntas selecionadas conforme os "macros indicadores" que produziram seis eixos temáticos. Além disso, baseou-se em um roteiro produzido pelo "Centro de Tecnologia de Edificações da Universidade do Sul de Santa Catarina para elaboração de um manual de Operação, Uso e Manutenção do Edifício”.

Os seis temas foram subdivididos em subtemas, a saber:

- equipamentos instalados - descrição, funções e acionamento;

- integração - equipamentos envolvidos e ambiências propiciadas;

- desempenho - controle e gerenciamento dos sistemas;

- interface - facilidade de manuseio, acesso remoto e pela rede mundial de computadores;

- manutenção - procedimentos e temporalidade;

- responsabilidades - empresas responsáveis pelo sistema e garantias.

Todos os subtemas foram contemplados com três questões cada, exceto os subtemas do tema três que teve quatro questões por item e, ainda, uma pergunta de opinião. Assim, a entrevista in loco totalizou o valor de quarenta e cinco questões, feitas igualitariamente a cada membro da família dos clientes respectivos das RA1, RA2, RA3 e RA4. Para maior compreensão e eficiência nas respostas dos usuários foi feito questionamento com respostas induzidas com valores que traduziram e valoraram o seu grau de apreensão do sistema de automação.

Nesse sentido, tentou-se valorar o grau de conhecimento a respeito dos temas e subtemas propostos no formato de "sei tudo sobre", "sei o suficiente sobre", "sei pouco sobre" e "não sei sobre". O usuário respondeu sobre seu conhecimento às afirmações ou constatações do sistema instalado em sua residência. Esse método facilitou tanto o entendimento por parte do usuário quanto para os pesquisadores, sem comprometer o objetivo da pesquisa.

$\mathrm{Na}$ sequência os dados foram tabulados e representados quantitativamente por porcentagens, relacionadas com o numero de pessoas e suas repostas frente ao grau de conhecimento sobre os subtemas propostos, obtidas por regra de três simples. O quadro um demonstra as porcentagens de cada resposta aos subtemas mencionados. 
Quadro 1 - Tabela resumo das respostas com a estatística obtida.

\begin{tabular}{|c|c|c|c|c|}
\hline \multirow{2}{*}{ Tema } & \multicolumn{4}{|c|}{ Grau de conhecimento sobre o tema } \\
\cline { 2 - 5 } & $\begin{array}{c}\text { Nenhum } \\
\text { conhecimento }\end{array}$ & $\begin{array}{c}\text { Pouco } \\
\text { conhecimento }\end{array}$ & $\begin{array}{c}\text { Conhecimento } \\
\text { suficiente }\end{array}$ & $\begin{array}{c}\text { Conhecimento } \\
\text { Total }\end{array}$ \\
\hline Equipamentos & $6.5 \%$ & $60 \%$ & $20 \%$ & $13.5 \%$ \\
\hline Integração & $6.5 \%$ & $47 \%$ & $40 \%$ & $6.5 \%$ \\
\hline Desempenho & $6.5 \%$ & $33.5 \%$ & $60 \%$ & - \\
\hline Interface & - & $67 \%$ & $26.5 \%$ & $6.5 \%$ \\
\hline Manutenção & $6.5 \%$ & $53.5 \%$ & $40 \%$ & - \\
\hline Responsabilidades & - & $40 \%$ & $60 \%$ & - \\
\hline
\end{tabular}

Fonte: Autores (2014)

Em análise aos resultados verificou-se que a maioria das respostas se concentrou entre as alternativas "conhecimento suficiente" e "pouco conhecimento", sendo esta última a com maior porcentagem de respostas pontuadas. Fora as questões já mencionadas apenas uma questão foi feita com resposta simples "sim e não". Perguntou-se a opinião do usuário entrevistados com relação a necessidade de um manual explicativo sobre o sistema de automação. A resposta - "sim" é necessário - foi em 100\% das entrevistas. Adotado o método já explanado de regra de três simples para resolução de proporções, em cada subtema abordado, reforçou-se o indicativo para a indispensabilidade de um manual pósinstalação para residências automatizadas.

\section{DIRETRIZES PARA O MANUAL PÓS-INSTALAÇÃO}

Como visto, os usuários da automação residencial estão desprovidos de conhecimento de conceitos gerais e específicos para manuseio e uso do sistema instalado. Para nortear e consequentemente dirimir duvida elaborar-se-á um roteiro com as diretrizes básicas para a elaboração de um manual para o proprietário. Lembra-se que, conforme De Araújo (2001):

[...] já é desenvolvido pela grande maioria de indústrias de outros setores. Muitas vezes as empresas oferecem este tipo de serviço aos seus clientes apenas para constar, ou seja, as informações não são claras e aquilo que deveria ajudar termina atrapalhando ou caindo em descrédito, sendo deixado de lado sem que o usuário leia. Baseado nestes fatos propõe-se que o manual seja sucinto [...] (DE ARAÚJO, 2001, p.03).

Defende-se que a avaliação do espaço automatizado deva ser compatível com os sistemas instalados e específicos desta nova tecnologia incremental da construção civil, ou seja, existirão diferenças nas perguntas ou na logística de reproduzir a avalição em função da unicidade de cada casa. Têm-se indicadores situacionais como a perenidade do sistema a integração e controle dos espaços, bem como a ambientação propiciada pela automação dos espaços podem ser fatores de avaliação responsáveis pela aceitação e manutenção desta inovação tecnológica. Assim, passa-se a expor o roteiro com as diretrizes necessárias a elaboração do Manual Pós-Instalação. 
Quadro 2 - Diretrizes para elaboração do Manual Pós-instalação.

\begin{tabular}{|c|c|c|}
\hline Tema & Capítulos do Manual & Assunto por Capítulos \\
\hline 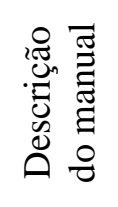 & Informações gerais & $\begin{array}{l}\text { Apresentação do Manual } \\
\text { Objetivos do Manual } \\
\text { Informações básicas sobre automação } \\
\text { Dúvidas frequentes }\end{array}$ \\
\hline \multirow{2}{*}{ 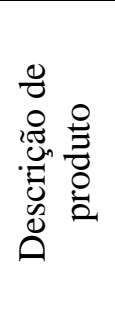 } & $\begin{array}{l}\text { Descrição dos } \\
\text { equipamentos } \\
\text { automatizados }\end{array}$ & $\begin{array}{c}\text { Funções de Cada Equipamento Instalado } \\
\text { Consumo e especificações } \\
\text { Modos de acionamento }\end{array}$ \\
\hline & $\begin{array}{l}\text { Descrição dos } \\
\text { equipamentos do } \\
\text { sistema de automação }\end{array}$ & $\begin{array}{c}\text { Funções de Cada Equipamento Instalado } \\
\text { Consumo e especificações } \\
\text { Modos de acionamento }\end{array}$ \\
\hline \multirow{4}{*}{ 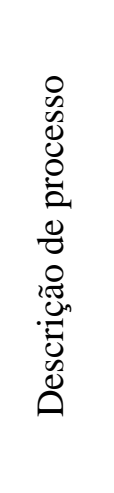 } & $\begin{array}{l}\text { Informação sobre a } \\
\text { integração do sistema }\end{array}$ & $\begin{array}{c}\text { Mapa do sistema integrado } \\
\text { Modos de Acionamento do Sistema }\end{array}$ \\
\hline & $\begin{array}{c}\text { Informação sobre o } \\
\text { desempenho do sistema }\end{array}$ & $\begin{array}{l}\text { Modos de monitoramento } \\
\text { Modos de gerenciamento }\end{array}$ \\
\hline & $\begin{array}{l}\text { Informações sobre o } \\
\text { modo de operação }\end{array}$ & $\begin{array}{l}\text { Acionamentos por Interfaces de Parede } \\
\text { Acionamentos por Interfaces Remotas } \\
\text { Acionamentos via rede mundial de computadores. }\end{array}$ \\
\hline & $\begin{array}{l}\text { Informações sobre } \\
\text { manutenção }\end{array}$ & $\begin{array}{c}\text { Periodicidade de Manutenção } \\
\text { Procedimentos para Casos de Falha no Sistema }\end{array}$ \\
\hline \multirow{2}{*}{ 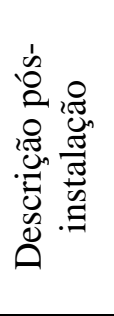 } & Responsabilidades & $\begin{array}{c}\text { Responsabilidades do Proprietário } \\
\text { Responsabilidades da Empresa Contratada } \\
\text { Técnicos e Empresa Responsáveis pela Manutenção da } \\
\text { Automação }\end{array}$ \\
\hline & Garantias & $\begin{array}{c}\text { Contatos sobre Fornecedores e Equipamentos Instalados } \\
\text { Termos de Garantia e Assistência Técnica } \\
\end{array}$ \\
\hline 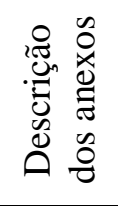 & Anexos necessários & $\begin{array}{c}\text { Contrato de Prestação de Serviços } \\
\text { Copia da Relação de Equipamentos e Serviços Adquiridos } \\
\text { Termo de Vistoria de Equipamentos Instalados } \\
\text { Planta Técnica do Sistema Implantado }\end{array}$ \\
\hline
\end{tabular}

Fonte: Autores (2014) baseados em De Araújo (2001)

Conclui-se que os usuários da automação residencial estão desprovidos de conhecimento de conceitos gerais e específicos do mecanismo. O mesmo padrão de desconhecimento repetiu-se nas quatro residências avaliadas, reforçando ainda mais o resultado final. Com isso é possível verificar a importância e necessidade de um manual pós-instalação para os clientes. Entretanto, como demonstra o roteiro proposto do quadro dois, o manual, em questão, deverá ser direcionado em prol das especificidades de cada sistema instalado, sendo que apenas alguns itens poderão ser padronizados para sua elaboração. 


\section{CONSIDERAÇÕES FINAIS}

Como qualquer novidade, a Automação Residencial inicialmente é percebida pelo cliente como um símbolo de status e modernidade. No momento seguinte, o conforto e a conveniência por ela proporcionados passam a ser decisivos. E por fim, ela se tornará uma necessidade vital e um fator de economia. Os sistemas de automação residencial necessitam ser seguros, confiáveis e principalmente possuírem um baixo custo de instalação. Assim sendo, cada projeto deve realizar a melhor combinação destas características, para que haja maior conforto e economia para o usuário.

Abre-se uma porta para pesquisas que identifiquem outras deficiências e temas para manuais voltados aos usuários que utilizam a automação em suas casas. Além do que, diminui os acionamentos assistenciais devido a problemas com o desconhecimento dos clientes, e que pode gerar dificuldades e trabalhos dispensáveis para os escritórios e empresas que trabalham na automação.

Este trabalho quer fomentar e a elaboração de um manual pós-instalação que, por elucidar as duvidas mais constantes dos usuários de automação, possibilita antecipar pontos de possíveis conflitos entre as empresas e o seus clientes. Ainda, estabelece um possível diferencial no marketing para as empresas de instalação de automação residencial. E finalmente contribuir para que esta inovação incremental da construção civil estabeleçase, cristalize-se e contribua aos vários segmentos que planejam ou executam os espaços com qualidade e eficiência.

\section{REFERÊNCIAS}

ASSOCIAÇÃO BRASILEIRA DE NORMAS TÉCNICAS. NBR 14037: Manual de operação, uso e manutenção das edificações: conteúdo e recomendações para elaboração e apresentação. Rio de Janeiro, 1998, 5p.

BOLZANI, Caio A. M. Residências Inteligentes: domótica, redes domésticas, automação residencial. São Paulo: Editora Livraria da Física, 2004, 332p.

DA SILVA, Danise S. Desenvolvimento e implementação de um sistema de supervisão e controle residencial. Dissertação (Mestrado) Programa de Pós-graduação em Engenharia Elétrica da Universidade Federal do Rio Grande do Norte, Natal-RN: a autora, 2009. Disponível em:<ftp://ftp.ufrn.br/pub/biblioteca/ext/bdtd/DaniseSS.pdf > Acesso em: 08 abr. 2014.

DE ARAÚJO, Hercules N., Manual do proprietário do imóvel: um exercício prático Artigo In: Anais Digitais XXIX COBENGE Congresso Brasileiro de Educação em Engenharia: PUCRS Porto Alegre: PURS, 2001. Disponível em: http://www.abenge.org.br/CobengeAnteriores/2001/trabalhos/MTE101.pdf > Acesso em: 10 abr. 2014.

FERRARI, Marilia; CLEMES, Mariana P.; MIRANDA, Maria E. S.; DA LUZ, Gabriela Y. Automação Residencial: a tecnologia em nosso favor. Florianópolis: as autoras, 2009 Monografia (Graduação) - Curso de Arquitetura e Urbanismo da Universidade Federal de Santa Catarina, Disponível em: <http://www.arq.ufsc.br/arq5661/trabalhos_20091/automacao_residencial/automacao_residencial.pdf> Acesso em 22 de jun. 2012.

LEITTE, Jamieson da P.; DA SILVA, Leonardo O.; MOREIRA, Marcos M.; DA SILVA, Roger R. Automadroid: automação residencial com dispositivos móveis. Artigo In: pt. scribd (website) Belém - PA: os autores, 2011. Disponível em: < http://pt.scribd.com/doc/202157885/AUTOMADROID-AUTOMACAO-RESIDENCIALCOM-DISPOSITIVOS-MOVEIS-pdf > Acesso em 15 mar. 2014.

MANUAL DE OSLO. Proposta de Diretrizes para Coleta e Interpretação de Dados sobre Inovação Tecnológica. (tradução de Paulo Garchet) $3^{\mathrm{a}}$.ed. Brasília: OECD\&OCDE/FINEP, 2005. 136p. 
MARCONI, Marina de A.; LAKATOS, Eva M. Técnicas de Pesquisa: planejamento e execução de pesquisas, amostragens e técnicas de pesquisa, elaboração, análise e interpretação de dados. 6 . ed. São Paulo: Atlas, 2006. 289 p.

MURATORI, José R.; DAL BÓ Paulo Henrique. Automação residencial: histórico, definições e conceitos. Artigo In: Instalações elétricas (website), São Paulo: os autores, 2011. Disponível em: < http://www.instalacoeseletricas.com/download/Automacao_residenciall.pdf> Acesso em: 25 mar. 2014

MURATORI, José R. Estamos preparados para a automação residencial? Artigo In: Instituto Brasileiro de Desenvolvimento de Arquitetura (website), São Paulo: o autor, 2012. Disponível em: <http://www.forumdaconstrucao.com.br/conteudo.php?a=11\&Cod=825> Acesso em: 06 fev. 2014.

OSÓRIO Arnóbio de S.; DANTAS FILHO Jussiê; SANTOS Maisa C.; PIMENTEL Victor C. de A. Automação residencial, (monografia)-Departamento de Engenharia Elétrica do rio Grande do Norte. Natal: os autores, 2010. Disponível em:< http://www.aureside.org.br/temastec/automacao_residencial_final.pdf > Acesso em 21 mar. 2014.

PAULA FILHO, Wilson De Padua. Multimidia: conceitos e aplicações. Rio de Janeiro: LTC Editora, 2000, 321p.

SCHMID, Aloísio Leoni. A Idéia do Conforto: reflexões sobre o ambiente construído. Curitiba: Pacto Ambiental, 2005, 339p.

SENA, Diane C. S. Automação Residencial. Trabalho de Conclusão de Curso (Graduação)Curso de Engenharia Elétrica da Universidade Federal do Espirito Santo, Vitória: a autora, 2005 Disponível em:

http://www2.ele.ufes.br/ projgrad/documentos/PG2005_2/dianecristinasouzasena.pdf > Acesso em 05 abr. 2014

TOFFLER, Alvin. O Choque do Futuro (tradução de Marco Aurélio de M. Matos). Rio de Janeiro: Editora Artenova S.A., 1973, 535p.

TUAN, Yi-Fu. Topofilia: um estudo da percepção, atitudes e valores do meio ambiente. São Paulo: Difusão Editorial do Livro, 1980. 288 p. 